\title{
Interaction between store-operated and arachidonate-activated calcium entry
}

\author{
Anthony M. Holmes ${ }^{\mathrm{a}}$, H. Llewelyn Roderick ${ }^{\mathrm{a}, \mathrm{b}, *}$, \\ Fraser McDonald ${ }^{\mathrm{c}}$, Martin D. Bootman ${ }^{\mathrm{a}}$ \\ ${ }^{a}$ The Babraham Institute, Laboratory of Molecular Signalling, Babraham, Cambridge CB2 4AT, UK \\ ${ }^{b}$ Department of Pharmacology, University of Cambridge, Tennis Court Road, Cambridge CB2 1PD, UK \\ ${ }^{\mathrm{c}}$ Department of Orthodontics, Floor 22, Guys Tower, Dental Institute of Kings College London, St. Thomas Street, London SE1 9RT, UK
}

Received 22 December 2005; received in revised form 22 March 2006; accepted 12 April 2006

Available online 12 June 2006

\begin{abstract}
A ubiquitous pathway for cellular $\mathrm{Ca}^{2+}$ influx involves 'store-operated channels' that respond to depletion of intracellular $\mathrm{Ca}^{2+}$ pools via an as yet unknown mechanism. Due to its wide-spread expression, store-operated $\mathrm{Ca}^{2+}$ entry (SOCE) has been considered a principal route for $\mathrm{Ca}^{2+}$ influx. However, recent evidence has suggested that alternative pathways, activated for example by lipid metabolites, are responsible for physiological $\mathrm{Ca}^{2+}$ influx. It is not clear if these messenger-activated $\mathrm{Ca}^{2+}$ entry routes exist in all cells and what interaction they have with SOCE. In the present study we demonstrate that HEK-293 cells and Saos-2 cells express an arachidonic acid (AA)-activated Ca ${ }^{2+}$ influx pathway that is distinct from SOCE on the basis of sensitivity to pharmacological blockers and depletion of cellular cholesterol. We examined the functional interaction between SOCE and the arachidonate-triggered $\mathrm{Ca}^{2+}$ influx (denoted non-SOCE). Both Ca ${ }^{2+}$ entry routes could underlie substantial long-lasting $\mathrm{Ca}^{2+}$ elevations. However, the two pathways could not operate simultaneously. With cells that had an on-going SOCE response, addition of arachidonate gave two profound effects. Firstly, it rapidly inhibited SOCE. Secondly, the mode of Ca ${ }^{2+}$ influx switched to the non-SOCE mechanism. Addition of arachidonate to naïve cells resulted in rapid activation of the non-SOCE pathway. However, this $\mathrm{Ca}^{2+}$ entry route was very slowly engaged if the SOCE pathway was already operative. These data indicate that the SOCE and arachidonate-activated non-SOCE pathways interact in an inhibitory manner. We probed the plausible mechanisms by which these two pathways may communicate.
\end{abstract}

(C) 2006 Elsevier Ltd. All rights reserved.

\section{Introduction}

Calcium $\left(\mathrm{Ca}^{2+}\right)$ is a ubiquitous intracellular messenger that controls a diverse range of cellular processes [1]. Cells have access to two sources of $\mathrm{Ca}^{2+}$ - finite stores located in intracellular organelles and a more substantial pool of extracellular $\mathrm{Ca}^{2+}$. In many cells types, release of $\mathrm{Ca}^{2+}$ from intracellular stores leads to the activation of a $\mathrm{Ca}^{2+}$ influx pathway denoted 'store-operated $\mathrm{Ca}^{2+}$ entry' (SOCE) [2]. This well-characterised $\mathrm{Ca}^{2+}$ entry mechanism is responsible for replenishing depleted intracellular stores and prolonging cellular $\mathrm{Ca}^{2+}$ signals [3]. Although the molecular identity of the

\footnotetext{
* Corresponding author. Tel.: +44 1223 496443; fax: +44 1223496033.

E-mail address: llewelyn.roderick@bbsrc.ac.uk (H.L. Roderick).
}

channels responsible for SOCE and their precise mechanism of activation is unclear, plausible candidates are members of the canonical transient receptor potential (TRPC) family $[3,4]$ with the involvement of stromal interaction molecule (STIM) [5]. This hypothesis is supported by several studies, which have demonstrated that ablation or heterologous expression of various TRPC isoforms/STIM can alter SOCE responses (e.g. [5-8]).

SOCE has been demonstrated using many different cell types during physiological stimulation or following depletion of intracellular $\mathrm{Ca}^{2+}$ stores using SERCA inhibitors such as thapsigargin $[2,3,9,10]$. The wide-spread expression of SOCE highlights its importance in replenishing intracellular $\mathrm{Ca}^{2+}$ pools after they have been discharged. However, it is becoming increasingly apparent that stimulation of cells 
with hormones that invoke the production of $\mathrm{Ca}^{2+}$-releasing messengers not only activates SOCE, but can also promote additional $\mathrm{Ca}^{2+}$ entry pathways $[11,12]$.

The intracellular messenger inositol 1,4,5-trisphosphate $\left(\mathrm{InsP}_{3}\right)$ is produced following hydrolysis of the minor membrane phospholipid phosphatidylinositol 4,5-bisphosphate $\left(\mathrm{PIP}_{2}\right)$. It is firmly established that $\mathrm{InsP}_{3}$ can release $\mathrm{Ca}^{2+}$ from intracellular stores and thereby trigger SOCE. $\mathrm{InsP}_{3}$ may also activate $\mathrm{Ca}^{2+}$ entry by binding to $\mathrm{InsP}_{3} \mathrm{Rs}$ located in the plasma membrane [13]. The other product of $\mathrm{PIP}_{2}$ hydrolysis is diacylglycerol (DAG). Unlike the water soluble InsP $\mathrm{P}_{3}$, DAG stays in the plane of the plasma membrane where it can activate protein kinase $\mathrm{C}$ (PKC), or be metabolised further. Both PKC and DAG (or membrane permeant analogues) have been demonstrated to cause $\mathrm{Ca}^{2+}$ influx distinct from SOCE in some cell types $[14,15]$. Furthermore, other messengers resulting from DAG metabolism, including $\mathrm{AA}$ and leukotrienes, activate non-store-operated $\mathrm{Ca}^{2+}$ influx [16-19].

Probably the best characterised non-SOCE activator is AA. Studies from several labs, including those of Shuttleworth [17,20], Taylor [16,21] and Putney [22], in addition to our own work [19], have demonstrated pathways for AAstimulated $\mathrm{Ca}^{2+}$ entry that are clearly distinct from SOCE. As with SOCE, the molecular targets of these messengers are not established, though TRPC isoforms have again been implicated. Although there are an increasing number of reports demonstrating significant $\mathrm{Ca}^{2+}$ influx via non-SOCE, it is presently unclear whether this is a general mechanism for $\mathrm{Ca}^{2+}$ entry. Furthermore, it is not fully established how cells utilise these distinct $\mathrm{Ca}^{2+}$ entry pathways during physiological signalling or how they interact.

In the present study, we sought to characterise the SOCE and arachidonate-activated non-SOCE pathways in HEK-293 and Saos- 2 cells. Our data indicate that these $\mathrm{Ca}^{2+}$ influx mechanisms are pharmacologically distinct, suggesting that they are separate entities. However, they functionally interact with each other. Essentially, SOCE and non-SOCE cannot operate simultaneously due to mutual antagonism, as proposed by other groups $[16,17,22]$. In contrast to other studies $[17,21]$, however, we observed that the reciprocal inhibition of the two $\mathrm{Ca}^{2+}$ entry pathways was not due to either elevated $\mathrm{Ca}^{2+}$ or nitric oxide (NO). Our data are consistent with a scheme in which arachidonate directly inhibits SOCE, and prior activation of SOCE substantially reduces the ability of the non-SOCE pathway to be engaged. Whenever AA is present, non-SOCE appears to be the dominant $\mathrm{Ca}^{2+}$ entry pathway.

\section{Materials and methods}

\subsection{Cell culture}

HEK-293 and Saos- 2 cells were grown at $37^{\circ} \mathrm{C}$ in Dulbecco's modified Eagle's medium supplemented with $10 \%$ heat-inactivated fetal bovine serum, $100 \mathrm{U} / \mathrm{ml}$ penicillin, $100 \mu \mathrm{g} / \mathrm{ml}$ streptomycin and $2 \mathrm{mM} \mathrm{L}$-glutamine in a humidified $95 \%$ air, $5 \% \mathrm{CO}_{2}$ incubator. All experimental procedures were carried out at room temperature $\left(20-22^{\circ} \mathrm{C}\right)$. Prior to imaging, the culture medium was replaced with an extracellular medium (EM) containing (mM): $\mathrm{NaCl}, 121 ; \mathrm{KCl}, 5.4$; $\mathrm{MgCl}_{2}, 0.8 ; \mathrm{CaCl}_{2}, 1.8 ; \mathrm{NaHCO}_{3}, 6$; D-glucose, 5.5; Hepes, 25; $\mathrm{pH} 7.3$.

\subsection{Video imaging}

Measurement of cytosolic $\mathrm{Ca}^{2+}$ in HEK-293 and Saos-2 cells was performed by monitoring fura- 2 fluorescence of cells adhered to glass coverslips using a PerkinElmer Life Sciences Ltd. (Seer Green, Beaconsfield, UK) imaging system. Fura- 2 was loaded into the cells by incubation with $2 \mu \mathrm{M}$ fura- 2 acetoxymethyl ester (30 min incubation followed by a 30-min period for de-esterification). A single glass coverslip with adherent cells was mounted on the stage of a Nikon Diaphot TE300 inverted epi-fluorescence microscope coupled to a xenon arc lamp. Fluorescence images were obtained using alternate excitation at 340 and $380 \mathrm{~nm}$. The excitation light was controlled by a Sutter filter changer (340HT15 and 380HT15; Sutter Industries). Emitted light was filtered at $510 \mathrm{~nm}$ and collected by a cooled Astrocam digital camera. The acquired images were stored and subsequently processed off-line with Ultraview software (PerkinElmer Life Sciences Ltd., UK).

\subsection{Manganese quench imaging}

Manganese $\left(\mathrm{Mn}^{2+}\right)$ entry was measured indirectly by recording the quench of fura-2 fluorescence when excited at $360 \mathrm{~nm}$. To minimize the effect of contaminating $\mathrm{Ca}^{2+}, \mathrm{Mn}^{2+}$ containing hepes buffer was supplemented with $1 \mathrm{mM}$ EGTA and the $\mathrm{Mn}^{2+}$ concentration was adjusted to avoid chelation of this ion. This was achieved using the web based programme MaxChelator (http://www.stanford.edu/ cpatton/ maxc.html). $2 \mathrm{mM} \mathrm{Mn^{2+ }}$ in the presence of $1 \mathrm{mM}$ EGTA equated to a free $\mathrm{Mn}^{2+}$ of $\sim 1 \mathrm{mM}$.

\subsection{Preparation and storage of $A A$}

Porcine liver AA ( $\mathrm{Na}^{+}$salt; Calbiochem) was dissolved in MilliQ water as a concentrated stock solution before being dispensed in aliquots then frozen and stored at $-20^{\circ} \mathrm{C}$ in a light-resistant container. Prior to use, an aliquot of AA was diluted to the required concentration by addition of EM containing $0.1 \%$ DMSO (to aid membrane permeability). All samples of AA were kept in the dark and on ice before use to suppress oxidation.

\subsection{Materials}

Thapsigargin, 2-aminoethoxydiphenyl borate (2-APB), gadolinium, SNP, L-NAME and calmidazolium were purchased from Sigma. LOE-908 ((R,S)-(3,4-dihydro-6,7-dime- 
thoxy-isochinolin-1yl)-2-phenyl- $N, N$-di[2-(2,3,4-trimethoxy phenyl) ethyl] acetamid mesylate) was generously given by Boehringer Ingelheim (Biberach an der Riss, Germany). Fura-2 was obtained from Invitrogen Molecular Probes. DAF-FM and NOC-18 were purchased from Calbiochem.

\subsection{Statistics}

Quantitative data are expressed as mean \pm S.E.M. For $\mathrm{Ca}^{2+}$ imaging experiments, representative traces are shown. These traces depict the most consistent pattern of response observed in multiple cells $(>30)$ imaged in at least three independent experiments. All experiments were repeated on different days. Statistical significance was determined by Student's $t$-test (calculated using GraphPad Prism, San Diego, USA).

\section{Results}

\subsection{Thapsigargin and AA activate pharmacologically distinct $\mathrm{Ca}^{2+}$ influx pathways}

Stimulation of HEK-293 or Saos-2 cells with $2 \mu$ M thapsigargin in $\mathrm{Ca}^{2+}$-free medium evoked a rapid transient mobi- lization of $\mathrm{Ca}^{2+}$ from intracellular stores (Fig. 1A). Subsequent superfusion of cells with $\mathrm{Ca}^{2+}$-containing medium led to a sustained cytosolic $\mathrm{Ca}^{2+}$ increase, indicative of SOCE (Fig. 1A). A similar pattern of response was observed if AA $(30 \mu \mathrm{M})$ was used instead of thapsigargin (Fig. 1B).

Although the patterns of $\mathrm{Ca}^{2+}$ responses evoked by thapsigargin and AA were alike in both HEK-293 and Saos- 2 cells, the $\mathrm{Ca}^{2+}$ signals were pharmacologically clearly distinct. In both cell types, the $\mathrm{Ca}^{2+}$ entry stimulated by thapsigargin was substantially inhibited by $100 \mu \mathrm{M} 2$-APB or $1 \mu \mathrm{M}$ $\mathrm{Gd}^{3+}$ (Fig. 1C and D), whilst the non-selective cation channel inhibitor LOE-908 $(100 \mu \mathrm{M})$ produced only a modest reduction in SOCE. With AA-stimulated $\mathrm{Ca}^{2+}$ entry, the sensitivity to these blockers was reversed; LOE-908 evoked a profound inhibition, whilst 2-APB and $\mathrm{Gd}^{3+}$ were relatively ineffective (Fig. 1C and D). These data indicate that AA activated a $\mathrm{Ca}^{2+}$ entry pathway that was pharmacologically distinct from SOCE. The responses to all concentrations of AA used in this study were reversible upon washout of the fatty acid. There was no significant loss of fura- 2 in cells incubated with 5-30 $\mu \mathrm{M}$ AA, suggesting that plasma membranes were not severely compromised by addition of the lipid.

To examine whether SOCE and AA-mediated $\mathrm{Ca}^{2+}$ entry could be simultaneously activated, cells were stimulated first with thapsigargin and then subsequently with AA. As
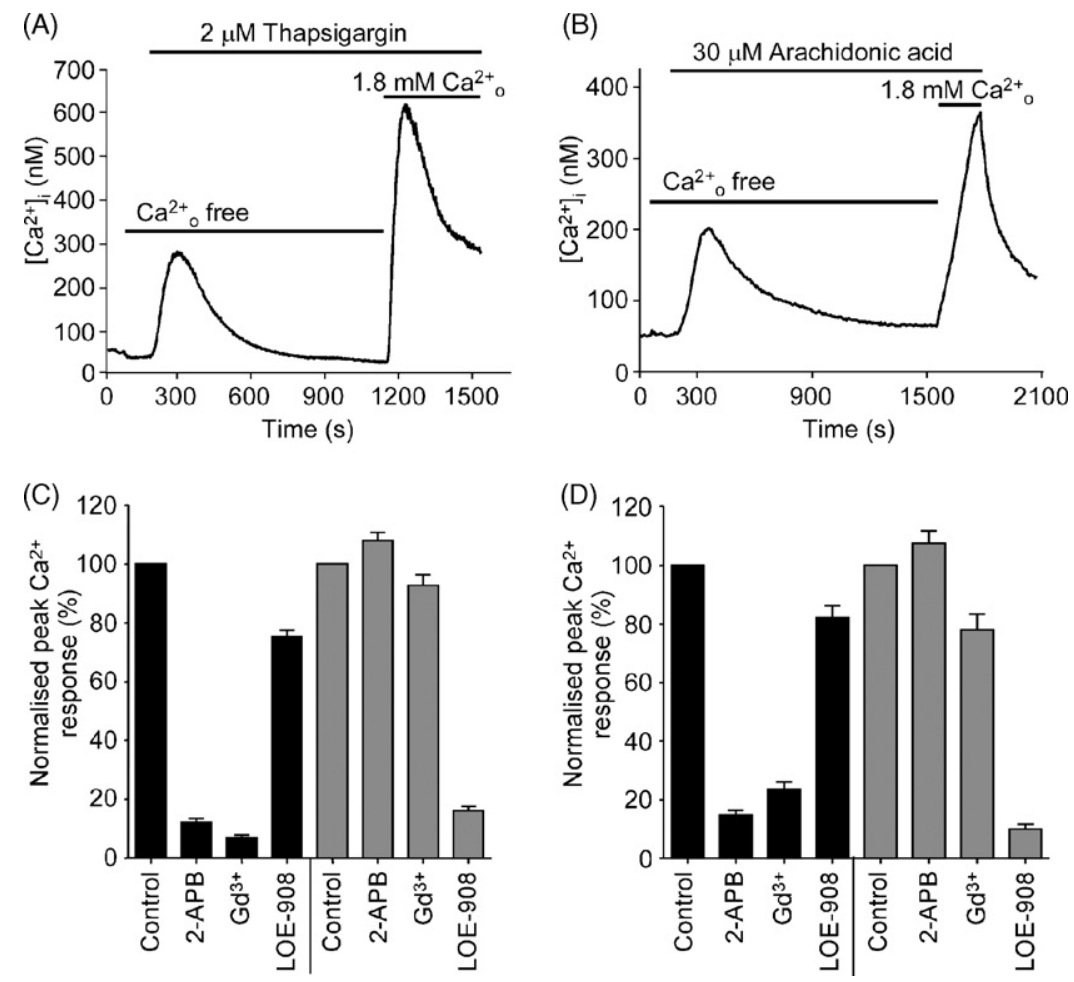

Fig. 1. $\mathrm{Ca}^{2+}$ influx evoked by thapsigargin and AA are pharmacologically distinct. HEK-293 cells were treated with either thapsigargin (A) or AA (B). In the absence of extracellular $\mathrm{Ca}^{2+}$, both agents evoked a transient increase in intracellular $\mathrm{Ca}^{2+}$ indicative of $\mathrm{Ca}^{2+}$ mobilization. Restoration of extracellular $\mathrm{Ca}^{2+}$ resulted in $\mathrm{Ca}^{2+}$ entry. The traces depict representative responses of single cells and are typical of at least 30 cells imaged in different experiments. Panels (C) and (D) depict the normalized $\mathrm{Ca}^{2+}$ influx response to thapsigargin (black bars) and AA (grey bars) in HEK-293 cells (C) and Saos-2 cells (D). The Ca ${ }^{2+}$ influx response was measured in the presence of the $\mathrm{Ca}^{2+}$ entry blockers indicated below each bar. Each antagonist was added 3 min prior to the restoration of extracellular $\mathrm{Ca}^{2+}$. The data represent mean \pm S.E.M. of at least 30 cells analyzed in three independent experiments. 

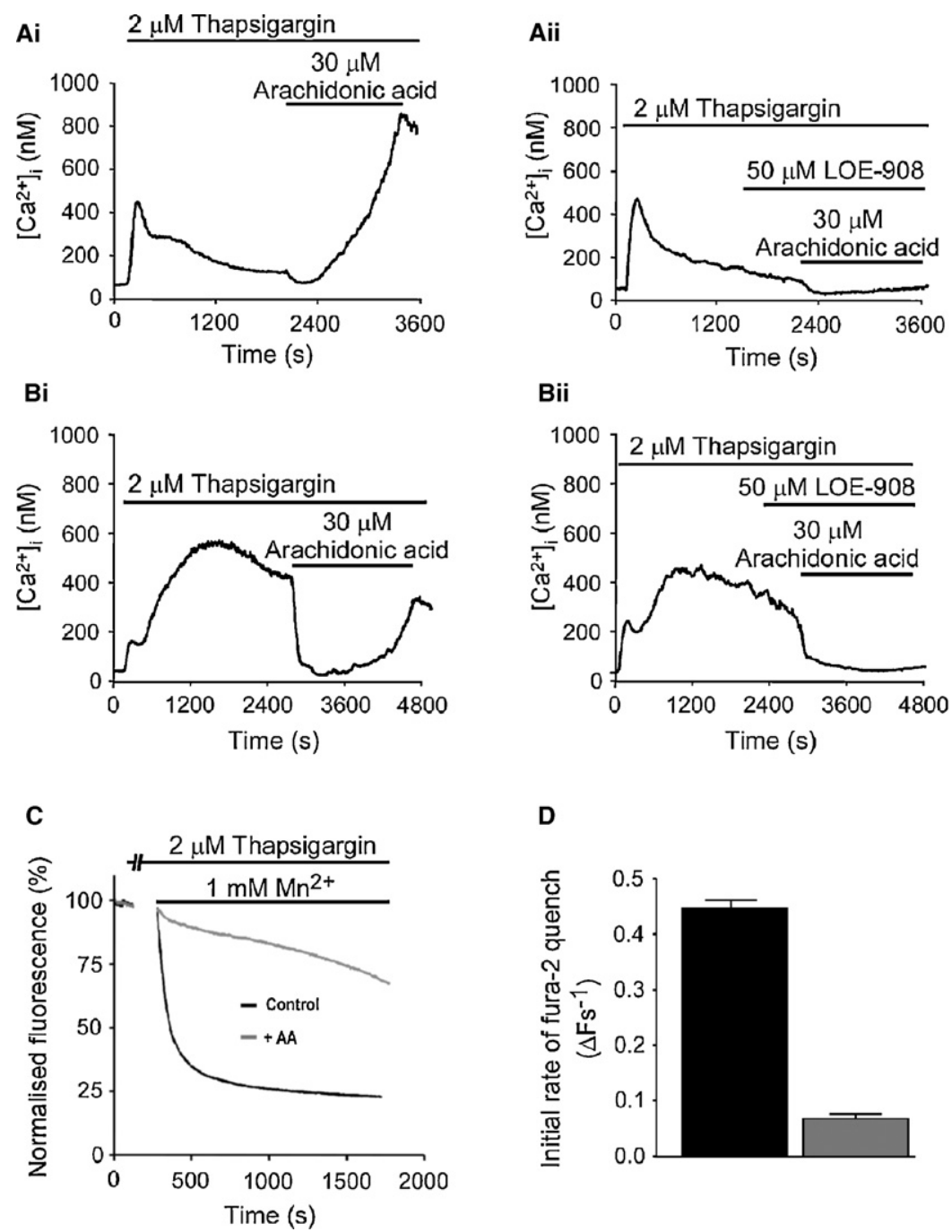

Fig. 2. AA inhibits thapsigargin-mediated SOCE and activates a pharmacologically distinct non-SOCE. HEK-293 cells (Ai) and Saos-2 cells (Bi) were treated with thapsigargin in the presence of extracellular $\mathrm{Ca}^{2+}$. This resulted in $\mathrm{Ca}^{2+}$ release followed by a sustained plateau of intracellular $\mathrm{Ca}^{2+} \mathrm{due}$ to SOCE . Subsequent addition of AA evoked a rapid inhibition of SOCE and the gradual activation of an alternative form of $\mathrm{Ca}^{2+}$ entry. The AA-induced $\mathrm{Ca}^{2+}$ entry was sensitive to LOE-908 in both HEK-293 (Aii) and Saos-2 (Bii) cells. (C) Thapsigargin-mediated $\mathrm{Mn}^{2+}$ entry was monitored in HEK-293 cells. The traces depict representative responses of single cells treated with thapsigargin alone (black trace) or thapsigargin $+30 \mu \mathrm{M}$ AA (grey trace). Quantitative analysis of the initial rate of fura-2 quench from experiments such as that illustrated in (C) is depicted in (D). The data represent the mean \pm S.E.M. of at least 40 cells analyzed in three independent experiments.

depicted in Fig. 2Ai and Bi for HEK-293 and Saos-2 cells, respectively, both agents evoked a similar pattern of response. Thapsigargin caused a rapid initial increase in cytosolic $\mathrm{Ca}^{2+}$ (due to release from stores), followed by a prolonged phase of $\mathrm{Ca}^{2+}$ entry. With the Saos-2 cells, but not the HEK-293 cells, the amplitude of the $\mathrm{Ca}^{2+}$ entry signal was substantially greater than the peak of the $\mathrm{Ca}^{2+}$ release. For both cell types, the addition of AA immediately reduced cytosolic $\mathrm{Ca}^{2+}$, consistent with a rapid inhibition of SOCE. Following this decline in $\mathrm{Ca}^{2+}$, there was a gradual re-emergence of $\mathrm{Ca}^{2+}$ influx, which could be inhibited by LOE-908 (Fig. 2Aii and Bii), demonstrating the activation of a distinct $\mathrm{Ca}^{2+}$ influx pathway and not simply a transient inhibition of SOCE. These data suggest that the $\mathrm{Ca}^{2+}$ entry pathways activated by thapsi- gargin and AA cannot be simultaneously activated; addition of AA to cells treated with thapsigargin rapidly curtails SOCE and slowly switches the pathway of entry to an LOE-908sensitive route.

To examine the unidirectional rate of cation entry more precisely, we supplemented the extracellular medium with $\mathrm{Mn}^{2+}$ and monitored the quench of fura- 2 as this ion entered cells. When HEK cells were stimulated with thapsigargin for 3 min, the subsequent addition of $\mathrm{Mn}^{2+}$ caused an almost instantaneous loss of fura-2 fluorescence (black trace in Fig. 2C). If AA was added simultaneously with thapsigargin, the initial rate of fura-2 quench was dramatically slowed (Fig. 2D and grey trace in Fig. 2C). The rate of fura-2 quench progressively increased after several minutes of incu- 
bation with thapsigargin and AA. These observations are consistent with the rapid inhibition of SOCE by AA followed by the slow development of an alternative cation entry pathway.

A further distinction between the SOCE and AA-mediated $\mathrm{Ca}^{2+}$ entry pathways was obvious following treatment of HEK-293 cells with methyl- $\beta$-cyclodextrin (M $\beta C D)$, an agent commonly used to extract cholesterol from plasma membranes and thereby disrupt lipid rafts [23]. Cells were preincubated with $\mathrm{M} \beta \mathrm{CD}$ (10 $\mathrm{mM}$ for $30 \mathrm{~min}$ ) before examining its effects on $\mathrm{Ca}^{2+}$ release and entry. Both thapsigargin and AA evoked higher amplitude $\mathrm{Ca}^{2+}$ release transients in cells treated with $\mathrm{M} \beta \mathrm{CD}$ (Fig. 3Ai and $\mathrm{Bi}$ ). In contrast, $\mathrm{Ca}^{2+}$ entry was significantly reduced by $\mathrm{M} \beta C D$. The peak amplitude of thapsigargin-evoked SOCE in control cells was $189 \pm 9 \mathrm{nM}$ ( $n=60$ cells $)$, this declined to $135 \pm 7 \mathrm{nM}$ ( $n=108$ cells) following M $\beta C D$ incubation (Fig. 3Aii). However, the consequence of $\mathrm{M} \beta \mathrm{CD}$ incubation on AA-mediated $\mathrm{Ca}^{2+}$ entry was even more dramatic. The robust $\mathrm{Ca}^{2+}$ entry evoked by AA in control cells (peak amplitude $335 \pm 45 \mathrm{nM}$; $n=37$ cells) was almost abolished in the presence of $\mathrm{M} \beta \mathrm{CD}$ (peak amplitude $18 \pm 3 \mathrm{nM} ; n=61$ cells).
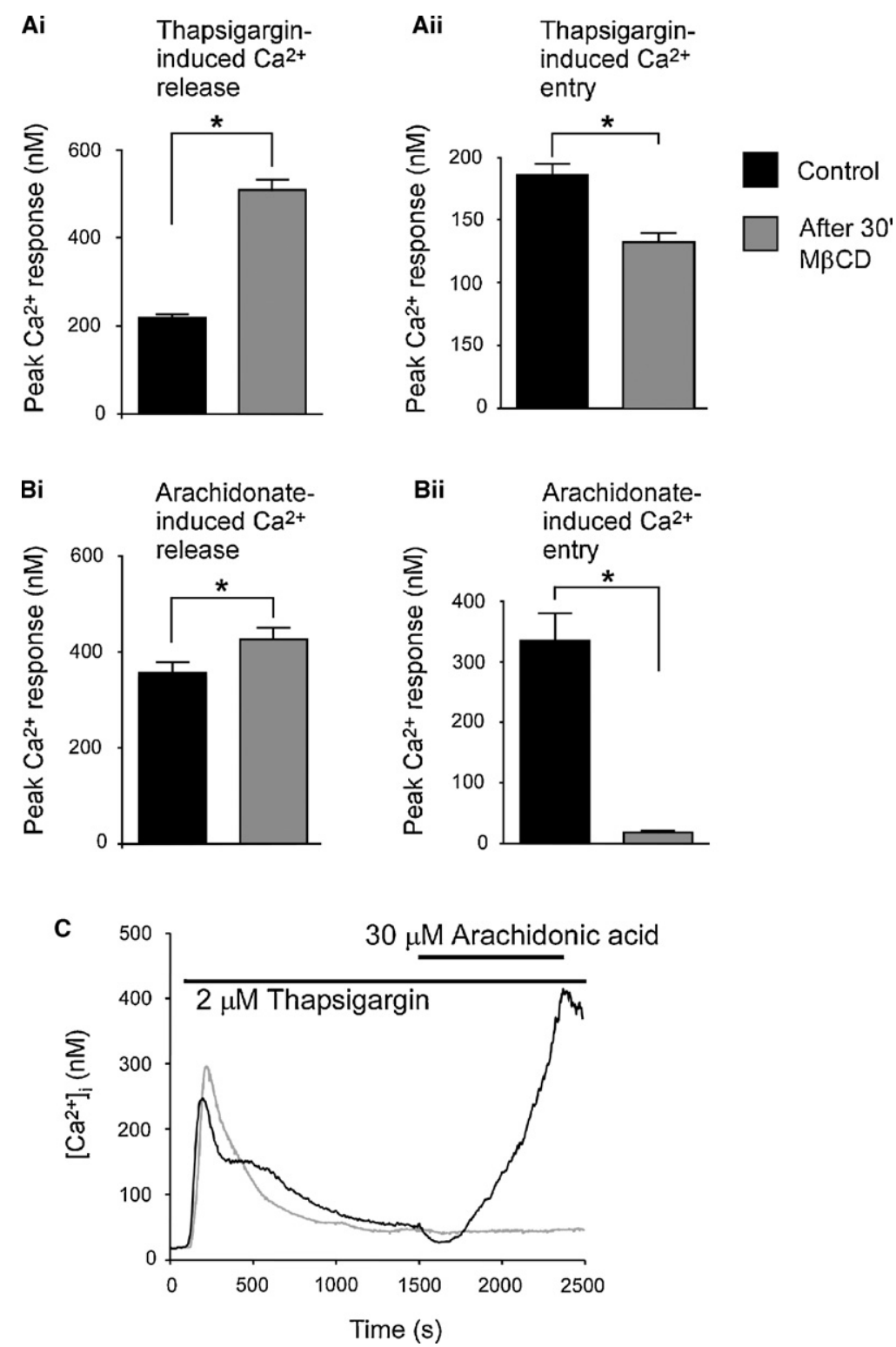

Fig. 3. Cholesterol depletion inhibits $\mathrm{Ca}^{2+}$ entry in HEK-293 cells. For depletion of cellular cholesterol, cells were incubated in $10 \mathrm{mM} \mathrm{M} \beta \mathrm{CD}$ for $30 \mathrm{~min}$ prior to imaging. Panels A and B show quantitative analysis of the effect of cholesterol depletion on thapsigargin-mediated (A) and AA-mediated (B) $\mathrm{Ca}^{2+}$ changes. The responses from control cells and M $\beta C D$-treated cells are indicated by black and grey bars, respectively. The data represent the mean \pm S.E.M. Statistical significance is denoted by ${ }^{*} p<0.05$. Panel $\mathrm{C}$ depicts a typical $\mathrm{Ca}^{2+}$ signal within an individual HEK-293 cell following M $\beta C D$ treatment (grey trace). A control response (black trace; taken from Fig. 2Ai) is superimposed for comparison. 
(A)

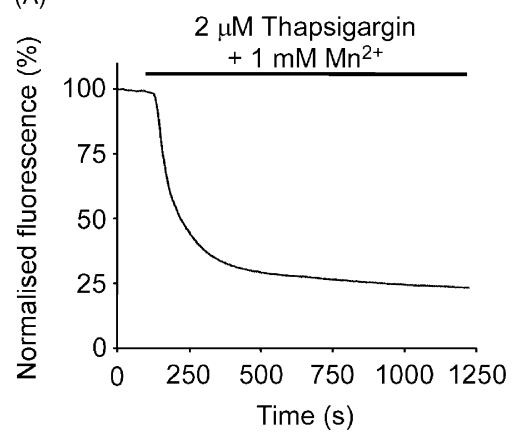

(B)

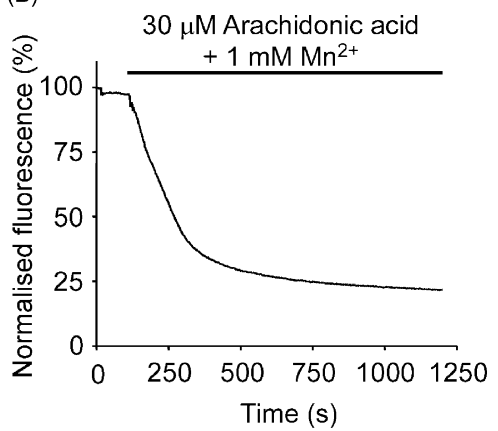

Fig. 4. Thapsigargin and AA activate rapid $\mathrm{Mn}^{2+}$ entry in naïve HEK-293 cells. The quench of fura- 2 fluorescence by $\mathrm{Mn}^{2+}$ was measured in cells treated with $2 \mu \mathrm{M}$ thapsigargin (A) or $30 \mu \mathrm{M}$ AA (B), as indicated by the bars above the traces. The panels depict representative single-cell responses, which were typical of at least 30 cells analyzed in three independent experiments.

The lack of effect of AA on cells incubated with $\mathrm{MBCD}$ is illustrated in Fig. 3C. Whereas addition of AA to cells displaying thapsigargin-evoked SOCE usually caused rapid inhibition of $\mathrm{Ca}^{2+}$ entry (Fig. 2), following MßCD treatment there was no effect (Fig. 3C). Furthermore, the substantial LOE-sensitive $\mathrm{Ca}^{2+}$ entry triggered by AA addition (Fig. 2) was completely prevented (Fig. 3C). These data suggest that depletion of cholesterol from the plasma membrane partially inhibits SOCE, but completely curtails the effects of AA.

\subsection{Prior activation of SOCE impacts on subsequent activation of AA-mediated $\mathrm{Ca}^{2+}$ entry}

As described above, application of $30 \mu \mathrm{M}$ AA to cells with an on-going SOCE response caused both a fast inhibition of SOCE and a slow switch to LOE-908-sensitive $\mathrm{Ca}^{2+}$ entry (e.g. Fig. 2). When applied to naïve cells, both thapsigargin and AA evoked a rapid $\mathrm{Mn}^{2+}$ entry response (Fig. 4A and B). The delayed development of AA-mediated $\mathrm{Ca}^{2+}$ entry following SOCE activation (Fig. 2) therefore contrasts with the ability of AA to trigger rapid cation influx in naïve cells.

We examined the effect of prior SOCE activation on $\mathrm{Ca}^{2+}$ influx triggered by a range of AA concentrations $(5,10$ or $30 \mu \mathrm{M})$. As illustrated in Fig. 5Ai, cells were initially stimulated with $\mathrm{AA}$ in $\mathrm{Ca}^{2+}$-free medium and extracellular $\mathrm{Ca}^{2+}$ was replenished after the decline of the $\mathrm{Ca}^{2+}$ release transient. The concentration-dependent effect of AA on $\mathrm{Ca}^{2+}$ entry is evident from the individual traces (Fig. 5Ai), the averaged rate of $\mathrm{Ca}^{2+}$ rise (Fig. 5B) and the peak amplitude of response (Fig. 5C).

When the same concentrations of AA were applied to cells in which SOCE had been previously activated by thapsigargin there was a significant reduction in the rate of AA-mediated $\mathrm{Ca}^{2+}$ entry (Fig. 5Aii and B). With $30 \mu \mathrm{M}$ AA, the development of the $\mathrm{Ca}^{2+}$ entry signal was slowed to the same rate as observed using $5 \mu \mathrm{M}$ AA on naïve cells (Fig. 5B). More striking, however, was the response to $5 \mu \mathrm{M}$ AA. Whereas this concentration of AA evoked a robust $\mathrm{Ca}^{2+}$ entry when given to cells without activated SOCE (Fig. 5Ai), when it was applied to cells with an on-going SOCE response there was a very modest AA-mediated $\mathrm{Ca}^{2+}$ entry (Fig. 5Aii and C). It therefore appears that when AA is given as the first stimulus it can trigger a rapid influx of $\mathrm{Ca}^{2+}$. Prior stimulation of SOCE inhibits subsequent activation of the AA-mediated pathway. Both the rate of increase of the $\mathrm{Ca}^{2+}$ rise and amplitude of the $\mathrm{Ca}^{2+}$ signal through the AA-evoked entry pathway are diminished by SOCE (Fig. 5B and C).

Although the $\mathrm{Ca}^{2+}$ influx evoked by AA was concentration dependent, its effect in inhibiting SOCE was not. Each of the AA concentrations used in this study $(5,10$ or $30 \mu \mathrm{M}$ ), appeared to fully inhibit SOCE since the cytosolic $\mathrm{Ca}^{2+}$ concentration always returned to basal levels before the LOE-908-sensitive $\mathrm{Ca}^{2+}$ entry developed (Figs. 2 and 5Aii).

\subsection{Elevation of cytosolic $\mathrm{Ca}^{2+}$ is not responsible for slowing non-SOCE}

Mignen and Shuttleworth [24] have proposed that $\mathrm{Ca}^{2+}$ influx through arachidonate-regulated $\mathrm{Ca}^{2+}$ (ARC) channels is inhibited by elevated intracellular $\mathrm{Ca}^{2+}$ levels. It is plausible therefore, that the $\mathrm{Ca}^{2+}$ signal arising from SOCE inhibited the subsequent development of AA-mediated $\mathrm{Ca}^{2+}$ entry. To examine this possibility, intracellular $\mathrm{Ca}^{2+}$ stores were passively depleted by incubating HEK-293 cells in $\mathrm{Ca}^{2+}$ free medium (nominally $\mathrm{Ca}^{2+}$ free supplemented with $1 \mathrm{mM}$ EGTA) for $2 \mathrm{~h}$ prior to imaging. This protocol was found to completely deplete the intracellular $\mathrm{Ca}^{2+}$ stores without a rise in cytosolic $\mathrm{Ca}^{2+}$ and consequently activate SOCE (data not shown). Subsequent addition of $30 \mu \mathrm{M}$ AA (simultaneous with restoration of extracellular $\mathrm{Ca}^{2+}$ ) resulted in a slowly rising $\mathrm{Ca}^{2+}$ entry signal (black trace in Fig. 6A), which was LOE-908 sensitive (grey trace in Fig. 6A). The rate of rise of the AA-induced $\mathrm{Ca}^{2+}$ signal in cells that had been preincubated in $\mathrm{Ca}^{2+}$-free medium for $2 \mathrm{~h}$ was $0.08 \pm 0.01 \mathrm{nM} \mathrm{s}^{-1}$ ( $n=17$ cells). This is similar to the sluggish development of $\mathrm{Ca}^{2+}$ influx when AA was applied following thapsigargin treatment $\left(0.156 \pm 0.01 \mathrm{nM} \mathrm{s}^{-1} ; n=71\right)$, and contrasts with the rapid activation of cation entry when the lipid was applied to naïve cells (Fig. 4). It therefore appears that activation of 

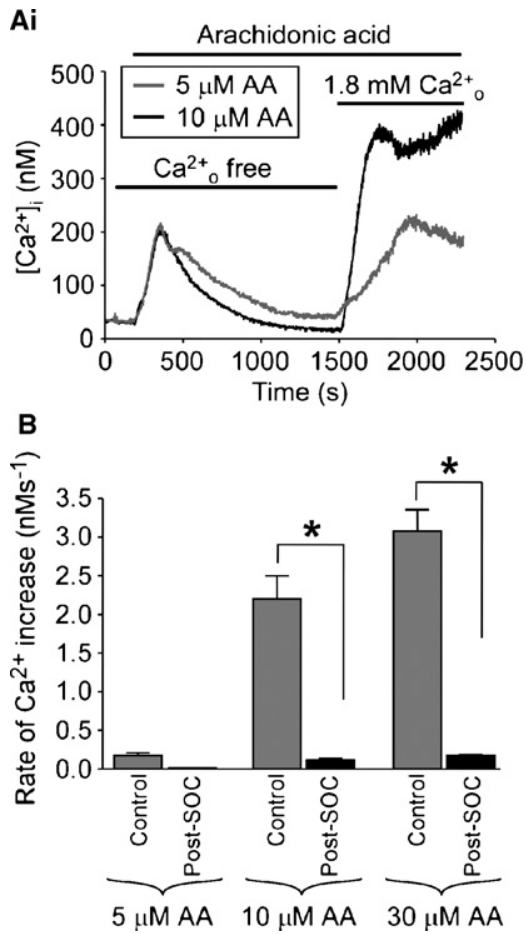

Aii

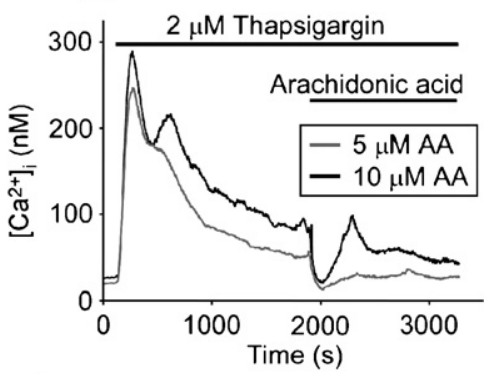

C

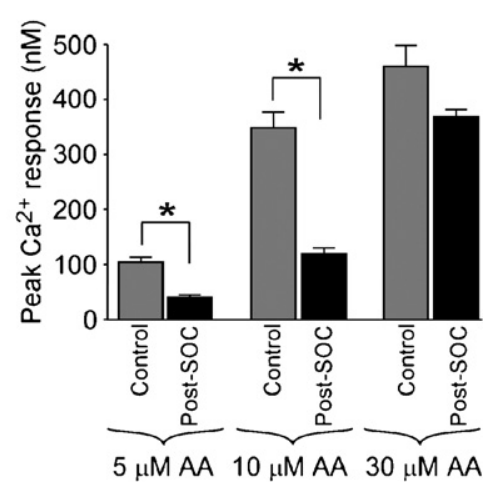

Fig. 5. Prior activation of SOCE impacts on subsequent activation of AA-mediated $\mathrm{Ca}^{2+}$ entry in HEK-293 cells. (Ai) Naïve cells were treated with $5 \mu \mathrm{M}$ (grey trace) or $10 \mu \mathrm{M}$ (black trace) AA. Both AA concentrations evoked a transient $\mathrm{Ca}^{2+}$ release signal of comparable amplitude and a substantial $\mathrm{Ca}^{2+}$ entry response when extracellular $\mathrm{Ca}^{2+}$ was restored. (Aii) The effects of $5 \mu \mathrm{M}$ (grey trace) and $10 \mu \mathrm{M}$ (black trace) AA were substantially reduced when added to cells with on-going SOCE. The traces depict representative responses of single cells. Quantitative analysis of the initial rate (B) and peak amplitude (C) of AA-mediated $\mathrm{Ca}^{2+}$ influx in naïve cells (grey bars) and cells pre-treated with thapsigargin (black bars) is shown. The data represent mean \pm S.E.M. of at least 30 cells analyzed in three independent experiments. Statistical significance is denoted by when ${ }^{*} p<0.01$.

(A)

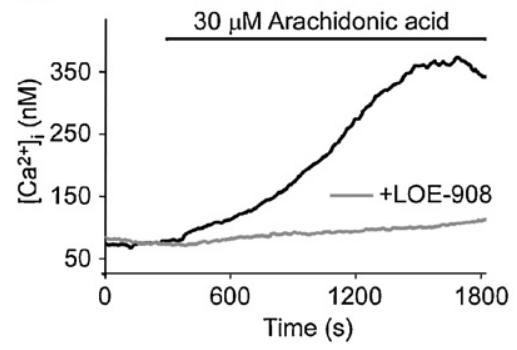

(C)

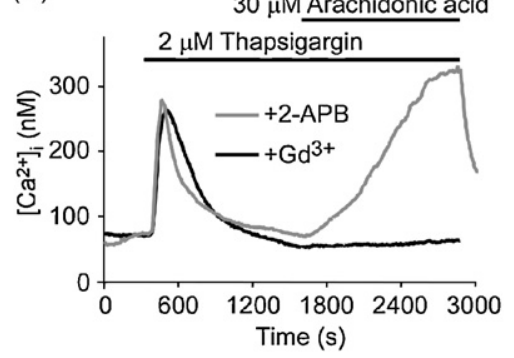

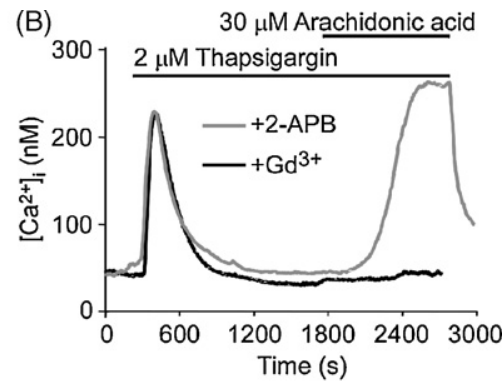

(D)

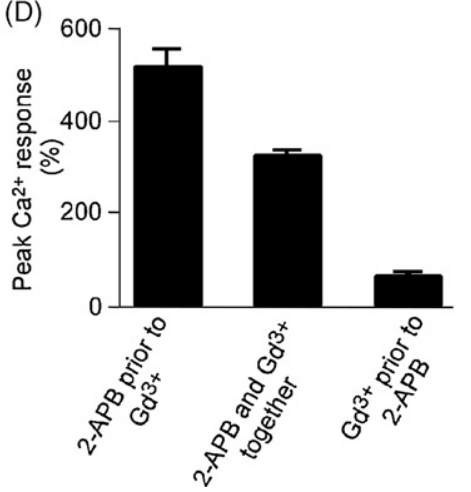

Fig. 6. Factors affecting AA-mediated $\mathrm{Ca}^{2+}$ entry. (A) Intracellular $\mathrm{Ca}^{2+}$ stores were passively depleted by incubation in $\mathrm{Ca}^{2+}$-free medium for $2 \mathrm{~h}$. Subsequently AA was added (simultaneous with the restoration of extracellular $\mathrm{Ca}^{2+}$ ). Panels $\mathrm{B}$ and $\mathrm{C}$ depict AA-mediated $\mathrm{Ca}^{2+}$ influx following SOCE activation in HEK-293 (B) and Saos-2 (C) cells in the presence of 2-APB (grey traces) or $\mathrm{Gd}^{3+}$ (black traces). The SOCE blockers were added 2 min prior to thapsigargin and were present throughout the remainder of the experiment. The traces depict representative responses of single cells. (D) Modulation of AA-induced Ca ${ }^{2+}$ entry by the order of addition of SOCE channel blockers. The data represent the mean \pm S.E.M. of at least 30 cells analyzed in three independent experiments. 
SOCE either by thapsigargin or passive depletion of stores has the same effect of slowing $\mathrm{Ca}^{2+}$ entry triggered by AA.

LOE-908 blocks AA-mediated $\mathrm{Ca}^{2+}$ entry, but does not affect $\mathrm{Ca}^{2+}$ release by AA (data not shown). Therefore, the lack of $\mathrm{Ca}^{2+}$ signal in cells challenged with AA + LOE-908 in Fig. 6A indicates that the $\mathrm{Ca}^{2+}$ stores were depleted by incubation in $\mathrm{Ca}^{2+}$-free medium for $2 \mathrm{~h}$. If this were not the case, a $\mathrm{Ca}^{2+}$ release transient would have been observed.

The data described above suggest that activation of SOCE per se, but not the flux of $\mathrm{Ca}^{2+}$ through the store-operated channels inhibits the development of AA-stimulated $\mathrm{Ca}^{2+}$ entry. To establish this more fully, we examined the effect of inhibitors of SOCE. HEK-293 cells were incubated with either $100 \mu \mathrm{M}$ 2-APB or $1 \mu \mathrm{M} \mathrm{Gd}^{3+}$ for 2 min prior to addition of $2 \mu \mathrm{M}$ thapsigargin. Due to the presence of the SOCE antagonists, the response to thapsigargin was reduced to an acute $\mathrm{Ca}^{2+}$ release transient (Fig. 6B). For cells stimulated with thapsigargin in the presence of 2-APB, the subsequent addition of AA led to a slowly developing LOE-908-sensitive $\mathrm{Ca}^{2+}$ entry signal (grey trace in Fig. 6B). This response was similar to the slow on-set of AA-mediated $\mathrm{Ca}^{2+}$ influx in cells where SOCE had been stimulated by thapsigargin or following passive $\mathrm{Ca}^{2+}$ store depletion. In contrast, for cells stimulated with thapsigargin in the presence of $1 \mu \mathrm{M} \mathrm{Gd} d^{3+}$ the subsequent addition of AA was without effect; there was no further change in cytosolic $\mathrm{Ca}^{2+}$ (black trace in Fig. 6B). A similar pattern of response was observed using 2-APB and $\mathrm{Gd}^{3+}$ on either HEK-293 cells (Fig. 6B) or Saos-2 cells (Fig. 6C). These data concur with the results presented earlier, in that prior activation of SOCE impacts on the subsequent induction of AA-mediated $\mathrm{Ca}^{2+}$ influx. Since 2-APB substantially inhibits $\mathrm{Ca}^{2+}$ entry via SOCE (Fig. 1), the results obtained using this antagonist support our contention that $\mathrm{Ca}^{2+}$ influx through store-operated channels is not responsible for the subsequent slow development of AA-stimulated $\mathrm{Ca}^{2+}$ entry.

The effect of $\mathrm{Gd}^{3+}$ appeared to be even more extreme in that inhibition of SOCE using this cation completely prevented activation of $\mathrm{Ca}^{2+}$ entry by AA. It is important to note that $\mathrm{Ca}^{2+}$ entry evoked by addition of AA to naïve cells was not substantially altered by $\mathrm{Gd}^{3+}$ (Fig. 1). Therefore, the complete block of AA-mediated $\mathrm{Ca}^{2+}$ entry by $\mathrm{Gd}^{3+}$ must be related to its effect on SOCE.

We examined whether 2-APB and $\mathrm{Gd}^{3+}$ had any overlap in their action by adding both inhibitors during the activation of SOCE, but changing the order in which they were applied. The protocol for these experiments was essentially to stimulate SOCE by application of $2 \mu \mathrm{M}$ thapsigargin for $10 \mathrm{~min}$. This was followed by the addition of 2-APB and/or $\mathrm{Gd}^{3+}$, and finally by superfusing cells with AA. When 2-APB was applied for $1 \mathrm{~min}$ before $\mathrm{Gd}^{3+}$, subsequent application of AA evoked the same slowly developing $\mathrm{Ca}^{2+}$ signal as observed when 2-APB was applied on its own (e.g. Fig. 6B). If $\mathrm{Gd}^{3+}$ was given simultaneously with 2-APB, the amplitude of the AA-mediated $\mathrm{Ca}^{2+}$ influx was significantly reduced (Fig. 6D). When $\mathrm{Gd}^{3+}$ was applied 1 min before 2-APB, the
$\mathrm{Ca}^{2+}$ rise evoked by AA was dramatically reduced. These results concur with an earlier study [22], and suggest that 2-APB and $\mathrm{Gd}^{3+}$ have a mutually exclusive effect on the stimulation of AA-mediated $\mathrm{Ca}^{2+}$ influx. Both agents effectively block SOCE. However, only 2-APB allows the mode of $\mathrm{Ca}^{2+}$ entry to be switched from SOCE to the LOE-sensitive AA-stimulated pathway. $\mathrm{Gd}^{3+}$ somehow restrains the activation of this mechanism. The profound effect of changing the order of addition of 2-APB and $\mathrm{Gd}^{3+}$ suggests that whichever antagonist reached its target first determined the subsequent activation status of the AA-mediated $\mathrm{Ca}^{2+}$ influx pathway.

\subsection{Calmidazolium rapidly switches SOCE to the LOE-908-sensitive $\mathrm{Ca}^{2+}$ entry pathway}

We have previously demonstrated that high concentrations $(\geq 10 \mu \mathrm{M})$ of calmidazolium activate the same $\mathrm{Ca}^{2+}$ entry pathway as AA [19]. The pharmacological profile of the $\mathrm{Ca}^{2+}$ entry pathway stimulated by calmidazolium [19] is the same as that shown for AA in the present study (Fig. 1). A typical response to calmidazolium is presented in Fig. 7A. When superfused over HEK-293 cells in $\mathrm{Ca}^{2+}$ free medium, $10 \mu \mathrm{M}$ calmidazolium evoked a rapid transient increase in intracellular $\mathrm{Ca}^{2+}$, which was followed by a robust $\mathrm{Ca}^{2+}$ entry signal when extracellular $\mathrm{Ca}^{2+}$ was
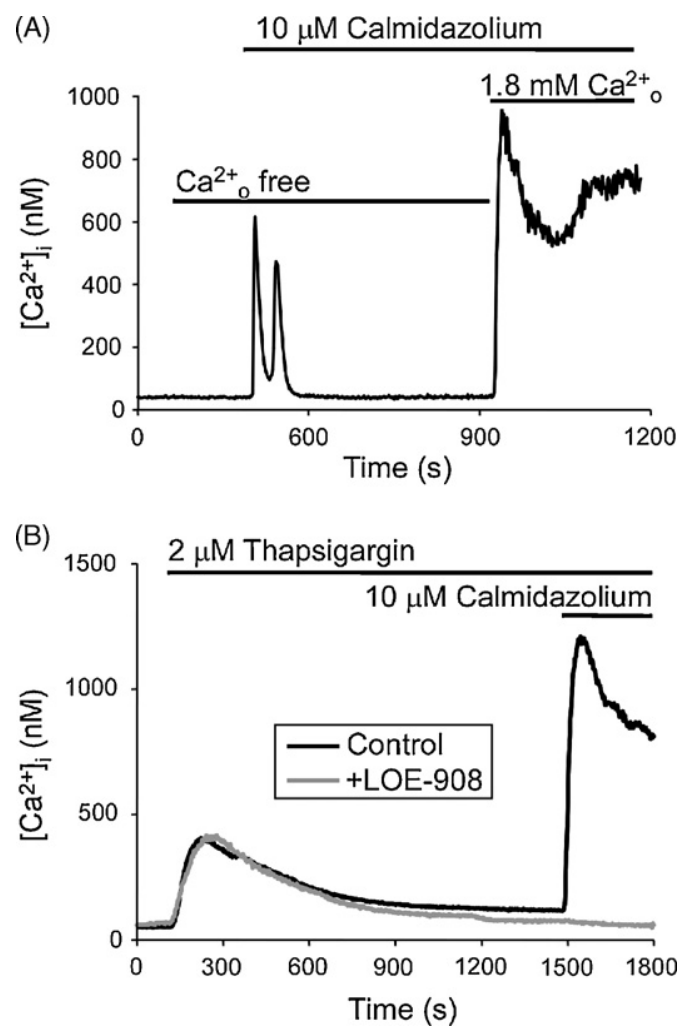

Fig. 7. Calmidazolium-activated $\mathrm{Ca}^{2+}$ influx. (A) $\mathrm{Ca}^{2+}$ mobilization and entry induced by $10 \mu \mathrm{M}$ calmidazolium. (B) Calmidazolium rapidly activated $\mathrm{Ca}^{2+}$ entry pathway following run down of SOCE (black trace) which was LOE-908 sensitive (grey trace). The traces depict representative responses of single cells. 
replaced (Fig. 7A). All cells responded in a similar manner $(n=28)$. Consistent with calmidazolium and AA stimulating the same $\mathrm{Ca}^{2+}$ influx pathway, preincubation of cells with $\mathrm{M} \beta C D(10 \mathrm{mM}$ for $30 \mathrm{~min})$ significantly reduced the amplitude of calmidazolium-induced $\mathrm{Ca}^{2+}$ influx. The peak $\mathrm{Ca}^{2+}$ signal evoked by calmidazolium in control cells was $704.62 \pm 81.49 \mathrm{nM}$ (mean \pm S.E.M., $n=28$ cells). This was reduced to $90.05 \pm 11.33 \mathrm{nM}(n=83$ cells $)$ following $\mathrm{M} \beta C D$ treatment.

With cells that had been treated with thapsigargin and therefore had an on-going SOCE response, application of calmidazolium caused a rapid $\mathrm{Ca}^{2+}$ entry signal (black trace in Fig. 7B). This $\mathrm{Ca}^{2+}$ influx was completely inhibited by $50 \mu \mathrm{M}$ LOE-908 (grey trace in Fig. 7B), indicating that calmidazolium had activated the pathway that AA can also stimulate. However, unlike the slow development of the LOE908-sensitive $\mathrm{Ca}^{2+}$ entry signal when AA was applied during SOCE (e.g. Fig. 2), calmidazolium caused an almost immediate changeover. A rapid switch from SOCE to non-SOCE was also observed in experiments where AA and calmidazolium were added together ( $n=78$ cells). These data indicate that the non-SOCE pathway was potentially functional following SOCE activation, but AA is not capable of rapidly engaging it whereas calmidazolium can.

\subsection{Effect of NO on SOCE and AA-mediated non-SOCE}

It has been suggested that NO may act to couple activation of AA-evoked non-SOCE with the simultaneous inhibition of SOCE [21]. We therefore examined whether this messenger was responsible for any aspects of the inhibitory communication observed between SOCE and non-SOCE in this study.

Production of NO resulting from AA or thapsigargin application was monitored using the fluorescent indicator DAF-FM. This molecule is essentially non-fluorescent until it reacts with the nitrosonium cation (produced by spontaneous oxidation of nitric oxide). The resulting fluorescent compound is trapped in the cytoplasm, so that DAF-FM fluorescence summates with continual NO production. Perfusion of cells with $30 \mu \mathrm{M}$ AA in $\mathrm{Ca}^{2+}$-containing media
(A)

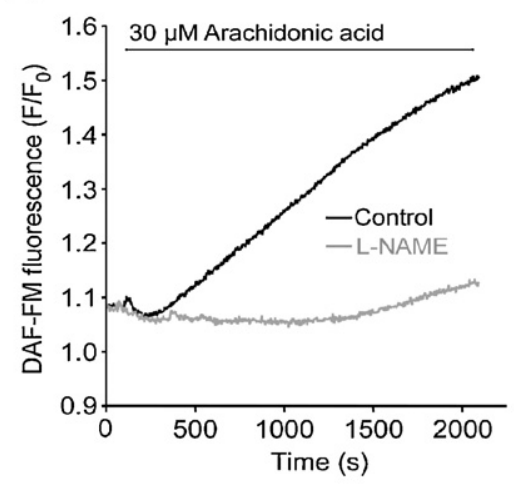

(C)

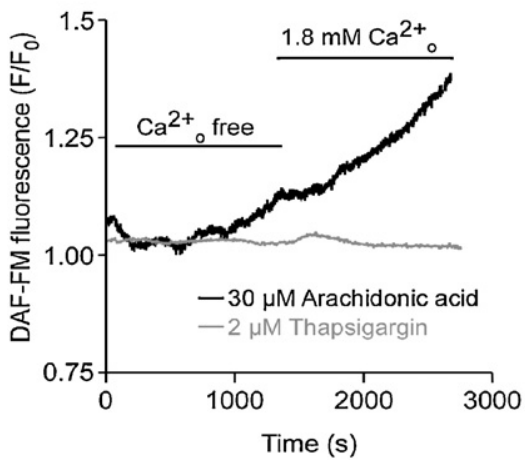

(B)

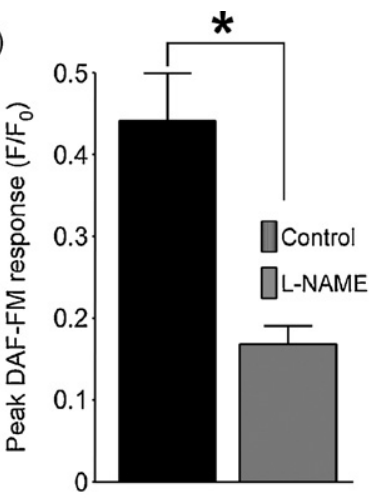

(D)

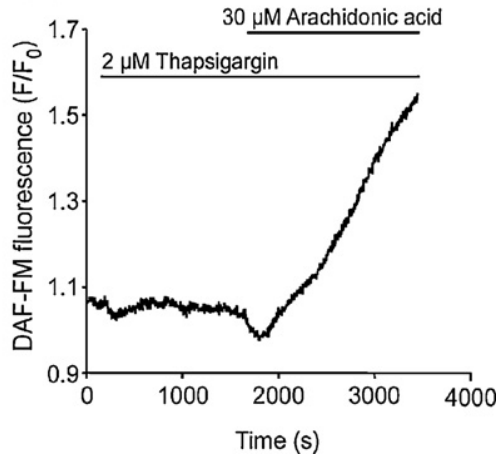

Fig. 8. AA, but not thapsigargin, increased intracellular levels of NO. HEK-293 cells were loaded with $5 \mu$ M DAF-FM prior to imaging. (A) Perfusion of cells with $30 \mu \mathrm{M}$ AA provoked an increase in DAF-FM fluorescence indicative of accumulation of NO (black trace). This response was inhibited by $100 \mu \mathrm{M}$ L-NAME (grey trace). (B) Quantitative analysis of the effect of AA (black bar) and AA + L-NAME (grey bar) on NO production. (C) Cells were treated with either AA $\left(30 \mu \mathrm{M}\right.$; black trace) or thapsigargin $\left(2 \mu \mathrm{M}\right.$; grey trace) in the absence and then presence of extracellular $\mathrm{Ca}^{2+}$. Only cells treated with AA displayed a change in DAF-FM fluorescence. The data represent the mean \pm S.E.M. of at least 30 cells analyzed in three independent experiments. Statistical significance is denoted by ${ }^{*} p<0.05$. (D) Cells were treated with $2 \mu \mathrm{M}$ thapsigargin in the presence of extracellular $\mathrm{Ca}^{2+}$ for sufficient time to allow SOCE to reach the plateau level observed in fura-2-imaging experiments. Subsequent addition of $30 \mu \mathrm{M}$ AA resulted in an increase in DAF-FM fluorescence. The traces depict representative responses of single cells. 
resulted in a steady increase in DAF-FM fluorescence signal. In the presence of L-NAME $(100 \mu \mathrm{M})$, which inhibits the NOproducing enzyme nitric oxide synthase (NOS) by competing with the natural substrate L-arginine, AA did not increase the DAF-FM signal (Fig. 8A and B). In contrast, thapsigargin did not provoke a change in DAF-FM fluorescence (Fig. 8C). AA also stimulated an increase in DAF-FM fluorescence in cells that had experienced prior treatment with thapsigargin (Fig. 8D). These data indicate that application of AA stimulated the production of $\mathrm{NO}$. Whereas, $\mathrm{Ca}^{2+}$ store depletion and SOCE did not.

The NO donors sodium nitroprusside (SNP; $100 \mu \mathrm{M}$ ) and 2,2'-(hydroxynitrosohydrazino)bis-ethanamine (NOC$18 ; 1 \mathrm{mM}$ ) were utilised to examine whether NO affected $\mathrm{Ca}^{2+}$ influx through SOCE or non-SOCE. Cells were treated with thapsigargin or $\mathrm{AA}$ in $\mathrm{Ca}^{2+}$-free medium to activate SOCE or non-SOCE, respectively. Following the decline of the $\mathrm{Ca}^{2+}$ release signal, the NO donors were added and 3 min later $\mathrm{Ca}^{2+}$ was readmitted to the external solution. Typical responses to these treatments are depicted in Fig. 9. Both SNP and NOC-18 caused a modest decrease in SOCE (Fig. 9B). With non-SOCE, SNP caused an increase in the $\mathrm{Ca}^{2+}$ influx signal, whereas NOC-18 had no discernable effect (Fig. 9D).
We examined whether NO contributed in any part to the effect of AA on SOCE, or the slow development of nonSOCE in cells where SOCE had been activated. An experimental protocol similar to that depicted in Fig. 2Ai was used, with the difference that L-NAME or NO donor (SNP or NOC-18) were applied 3 min prior to AA addition. When L-NAME was used 11 out of 30 cells displayed a faster onset of AA-evoked $\mathrm{Ca}^{2+}$ entry. Conversely, if SNP or NOC-18 were applied before AA addition, a number of cells (SNP, 1 out of 30; NOC-18, 4 out of 30) had a slower on-set of non-SOCE. These data could suggest that NO had a modest controlling influence on the inhibition of SOCE and triggering of non-SOCE in response to AA addition. However, the majority of cells were not affected by either L-NAME or NO addition, and the $\mathrm{Ca}^{2+}$ changes resembled the response shown in Fig. 2Ai.

\section{Discussion}

Consistent with other reports $[16,17,22,25]$, the data in this study demonstrate that electrically non-excitable cells (HEK and Saos-2) express distinct SOCE and AA-activated nonSOCE pathways, which interact in a mutually antagonistic

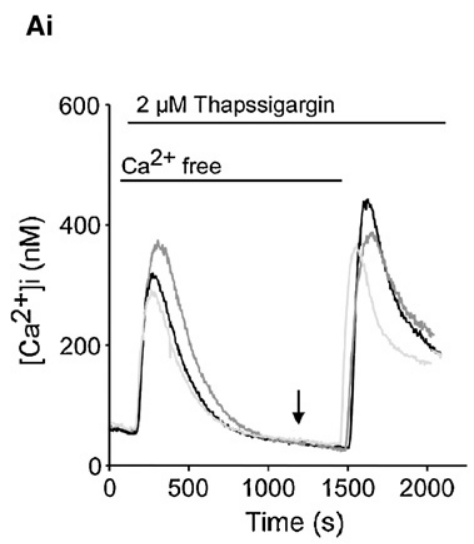

ii
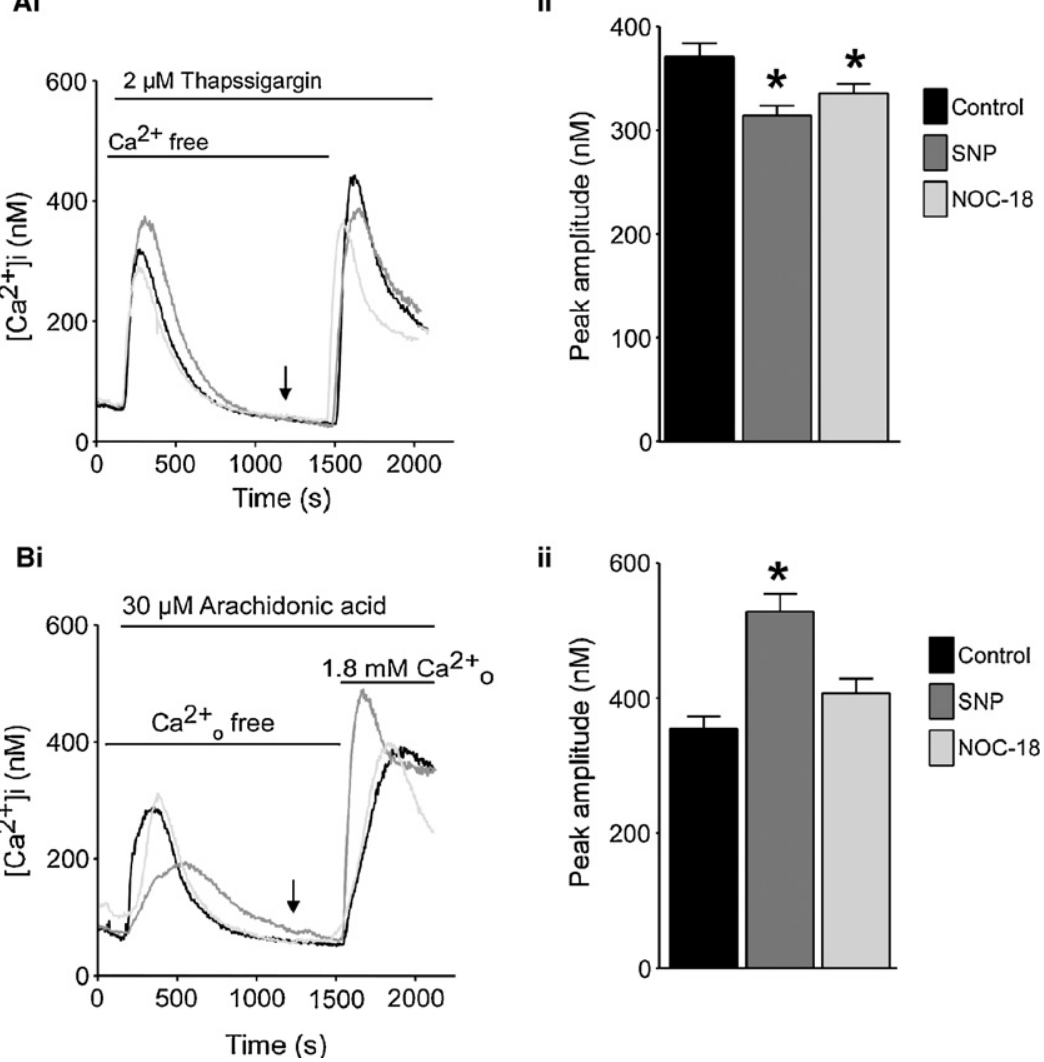

Fig. 9. Effect of $\mathrm{NO}$ donors on $\mathrm{Ca}^{2+}$ entry in naïve cells. Panels A and B depict $\mathrm{Ca}^{2+}$ entry responses in cells stimulated with thapsigargin (A) or AA (B) in the absence (control; black traces and bars) or presence (grey traces and bars) of NO donors. The timing for addition of NO donors is indicated by the arrows. The traces illustrate representative responses from single cells. Panels Aii and Bii show quantitative analysis of the experiments depicted in Ai and Bi, respectively. The data represent mean \pm S.E.M. of at least 30 cells analyzed in three independent experiments. Statistical significance is denoted by ${ }^{*} p<0.05$. 
manner. The SOCE and non-SOCE pathways were distinguished on the basis of the sensitivity to pharmacological blockers ( $\mathrm{Gd}^{3+}, 2$-APB, LOE-908; Fig. 1) and depletion of cellular cholesterol using M $\beta C D$ (Fig. 3). Both $\mathrm{Ca}^{2+}$ influx pathways could be rapidly activated in naïve cells (Fig. 4), and either route could give rise to long-lasting substantial $\mathrm{Ca}^{2+}$ entry signals (Fig. 1). The SOCE and non-SOCE pathways could not be activated simultaneously. Addition of AA to an on-going thapsigargin-mediated SOCE signal rapidly curtailed $\mathrm{Ca}^{2+}$ influx, and switched the mode of $\mathrm{Ca}^{2+}$ entry to the LOE-908-sensitive pathway (Fig. 2). Even with $5 \mu \mathrm{M}$ AA, the inhibition of SOCE was rapid and complete (Fig. 5).

The mechanism underlying the inhibition of SOCE by AA is unclear. It has been suggested that NO, either directly or via stimulation of guanylate cyclase and protein kinase $\mathrm{G}$, acts as a messenger downstream of AA to inhibit SOCE $[21,25]$. Consistent with that scheme, we observed that AA stimulated the production of NO (Fig. 8). However, in the present study exogenous application of substantial concentrations of NO donors did not fully inhibit SOCE (Fig. 9). Furthermore, incubation of cells with L-NAME or NO donors before addition of AA did not prevent the rapid inhibition of SOCE in the majority of cells (see Section 3). It therefore appears unlikely that the NO production stimulated by AA was responsible for the effects of the lipid on SOCE. This contention is also supported by the observation that the inhibition of SOCE occurred immediately upon addition of AA and was complete within a few tens of seconds (Fig. 5Aii), whereas the production of $\mathrm{NO}$ developed over a slower time course (Fig. 8). The inhibition of SOCE by AA is unlikely to involve $\mathrm{Ca}^{2+}$, since AA caused the cytoplasmic $\mathrm{Ca}^{2+}$ concentration to return to basal levels before the non-SOCE pathway developed. This suggests that immediately following AA addition there was a period with no $\mathrm{Ca}^{2+}$ influx at all. The simplest mechanism to explain our observations is that AA inhibits SOCE channels by direct interaction or altering their lipid environment, as has been previously proposed [26,27].

In addition to AA inhibiting SOCE, we observed that SOCE impacted on the development of AA-activated $\mathrm{Ca}^{2+}$ influx. Naïve cells displayed a rapidly rising $\mathrm{Ca}^{2+}$ entry signal when incubated with 5-30 $\mu \mathrm{M}$ AA (Figs. 1 and 5). In contrast, LOE-sensitive $\mathrm{Ca}^{2+}$ entry developed slowly in cells where SOCE was already activated (Fig. 5). With $5 \mu \mathrm{M} \mathrm{AA}$, the prior activation of SOCE reduced the subsequent nonSOCE signal to almost negligible levels (Fig. 5Aii).

It has been suggested that $\mathrm{AA}$-stimulated $\mathrm{Ca}^{2+}$ entry is substantially inhibited by cytosolic $\mathrm{Ca}^{2+}$ concentrations $>100 \mathrm{nM}$ [17], and that this effect is mediated by activation of $\mathrm{Ca}^{2+}$-sensitive phosphatase calcineurin [28]. We therefore considered that the slow development of non-SOCE in cells where SOCE was active could have been due to the elevation of cytosolic $\mathrm{Ca}^{2+}$. However, passive depletion of intracellular $\mathrm{Ca}^{2+}$ stores by incubating cells in $\mathrm{Ca}^{2+}$-free medium had the same effect. It therefore appears that even without a cor- responding $\mathrm{Ca}^{2+}$ rise, prior activation of SOCE significantly slows the ability of the non-SOCE mechanism to develop.

Calmidazolium caused the rapid activation of LOEsensitive $\mathrm{Ca}^{2+}$ entry, even in cells where SOCE was already activated (Fig. 7). It is unclear why calmidazolium can override the effect of SOCE and rapidly engage the non-SOCE pathway, whereas AA cannot. Our previous work demonstrated that calmidazolium-induced $\mathrm{Ca}^{2+}$ entry was dependent on AA production via $\mathrm{iPLA}_{2}$, and that metabolism of AA was not required to activate the LOE-908-sensitive $\mathrm{Ca}^{2+}$ entry mechanism [19]. It therefore appears that AA and calmidazolium operate via exactly the same non-SOCE $\mathrm{Ca}^{2+}$ influx mechanism. However, calmidazolium clearly has some action, perhaps related to its effect as a calmodulin antagonist, which enables it to rapidly recruit the non-SOCE pathway, and is not shared by AA.

The specific cellular localization of SOCE and non-SOCE channels is unknown, and cannot be fully analyzed until the molecular entities that form these pathways are established. However, several TRPC isoforms have been localized within cholesterol-rich microdomains in the plasma membrane termed lipid rafts [29-31]. Depletion of these cholesterol-rich domains results in a reduction of $\mathrm{Ca}^{2+}$ entry in a number of cell types [32-34]. We observed that sequestering cholesterol reduced both SOCE and non-SOCE. Interestingly, although SOCE was significantly reduced following cholesterol depletion (Fig. 3A), non-SOCE was almost completely inhibited (Fig. 3B). These data could suggest that the SOCE and non-SOCE channels are differentially sensitive to cholesterol in their lipid environment, or that the non-SOCE channels are more abundantly expressed in lipid rafts and are thereby particularly sensitive to their disruption.

In summary, our data agree with previous studies that electrically non-excitable cells express both SOCE and nonSOCE, and that these influx pathways cannot be simultaneously activated $[16,17,22]$. However, our results do not concur with observations that $\mathrm{NO}$ or $\mathrm{Ca}^{2+}$ underlie the communication between the pathways. We envisage a scheme whereby cells express channels that are independently sensitive to store depletion or AA, but which share components that are critical for activation. In naïve cells, the apparatus for either $\mathrm{Ca}^{2+}$ influx pathway can be rapidly recruited. However, once the SOCE or non-SOCE mechanism is engaged, the proteins are effectively trapped in that particular channel configuration. Addition of AA to a cell with an on-going SOCE response immediately terminates $\mathrm{Ca}^{2+}$ influx due to an effect on SOCE channels [26,27], and then slowly recruits the protein(s) required for the non-SOCE pathway. We suggest that adding $\mathrm{Gd}^{3+}$ stabilizes the SOCE apparatus such that AA can no longer recruit the necessary components to form a viable $\mathrm{Ca}^{2+}$ entry channel. In contrast, although 2APB blocks the SOCE pathway to the same extent as $\mathrm{Gd}^{3+}$, it does not stabilize SOCE in the same manner. This putative mechanism fits our data, but remains speculative until the molecular components of SOCE and AA-mediated nonSOCE are established in the future. 


\section{Acknowledgements}

This work was funded by the BBSRC and HFSP (grant RGP71/2002). HLR is supported by a Royal Society University Research Fellowship.

\section{References}

[1] M.J. Berridge, M.D. Bootman, H.L. Roderick, Calcium signalling: dynamics, homeostasis and remodelling, Nat. Rev. Mol. Cell Biol. 4 (2003) 517-529.

[2] J.W. Putney Jr., L.M. Broad, F.J. Braun, J.P. Lievremont, G.S. Bird, Mechanisms of capacitative calcium entry, J. Cell Sci. 114 (2001) 2223-2229.

[3] K. Venkatachalam, D.B. van Rossum, R.L. Patterson, H.T. Ma, D.L. Gill, The cellular and molecular basis of store-operated calcium entry, Nat. Cell Biol. 4 (2002) E263-E272.

[4] B. Nilius, From TRPs to SOCs, CCEs, and CRACs: consensus and controversies, Cell Calcium 33 (2003) 293-298.

[5] J. Roos, P.J. DiGregorio, A.V. Yeromin, K. Ohlsen, M. Lioudyno, S. Zhang, O. Safrina, J.A. Kozak, S.L. Wagner, M.D. Cahalan, G. Velicelebi, K.A. Stauderman, STIM1, an essential and conserved component of store-operated $\mathrm{Ca}^{2+}$ channel function, J. Cell Biol. 169 (2005) 435-445.

[6] M. Freichel, S.H. Suh, A. Pfeifer, U. Schweig, C. Trost, P. Weissgerber, M. Biel, S. Philipp, D. Freise, G. Droogmans, F. Hofmann, V. Flockerzi, B. Nilius, Lack of an endothelial store-operated $\mathrm{Ca}^{2+}$ current impairs agonist-dependent vasorelaxation in TRP4-/- mice, Nat. Cell Biol. 3 (2001) 121-127.

[7] C. Tiruppathi, M. Freichel, S.M. Vogel, B.C. Paria, D. Mehta, V. Flockerzi, A.B. Malik, Impairment of store-operated $\mathrm{Ca}^{2+}$ entry in TRPC4(-/-) mice interferes with increase in lung microvascular permeability, Circ. Res. 91 (2002) 70-76.

[8] X. Wu, G. Babnigg, T. Zagranichnaya, M.L. Villereal, The role of endogenous human Trp4 in regulating carbachol-induced calcium oscillations in HEK-293 cells, J. Biol. Chem. 277 (2002) 1359713608.

[9] M.J. Berridge, Capacitative calcium entry, Biochem. J. 312 (Pt 1) (1995) $1-11$.

[10] L. Birnbaumer, G. Boulay, D. Brown, M. Jiang, A. Dietrich, K. Mikoshiba, X. Zhu, N. Qin, Mechanism of capacitative $\mathrm{Ca}^{2+}$ entry (CCE): interaction between IP3 receptor and TRP links the internal calcium storage compartment to plasma membrane CCE channels, Recent Prog. Horm. Res. 55 (2000) 127-161 (discussion 161-162).

[11] M.D. Bootman, M.J. Berridge, H.L. Roderick, Calcium signalling: more messengers, more channels, more complexity, Curr. Biol. 12 (2002) R563-R565.

[12] T.J. Shuttleworth, What drives calcium entry during $\left[\mathrm{Ca}^{2+}\right] \mathrm{i}$ oscillations?-challenging the capacitative model, Cell Calcium 25 (1999) 237-246.

[13] G. Vazquez, B.J. Wedel, G.S. Bird, S.K. Joseph, J.W. Putney, An inositol 1,4,5-trisphosphate receptor-dependent cation entry pathway in DT40 B lymphocytes, EMBO J. 21 (2002) 4531-4538.

[14] J.A. Rosado, S.O. Sage, Protein kinase C activates non-capacitative calcium entry in human platelets, J. Physiol. 529 (Pt 1) (2000) 159169.

[15] Y. Tesfai, H.M. Brereton, G.J. Barritt, A diacylglycerol-activated $\mathrm{Ca}^{2+}$ channel in PC12 cells (an adrenal chromaffin cell line) correlates with expression of the TRP-6 (transient receptor potential) protein, Biochem. J. 358 (2001) 717-726.
[16] Z. Moneer, C.W. Taylor, Reciprocal regulation of capacitative and noncapacitative $\mathrm{Ca}^{2+}$ entry in A7r5 vascular smooth muscle cells: only the latter operates during receptor activation, Biochem. J. 362 (2002) $13-21$.

[17] O. Mignen, J.L. Thompson, T.J. Shuttleworth, Reciprocal regulation of capacitative and arachidonate-regulated noncapacitative $\mathrm{Ca}^{2+}$ entry pathways, J. Biol. Chem. 276 (2001) 35676-35683.

[18] M.P. Peppelenbosch, J.L. Tertoolen, J. den Hertog, S.W. de Laat, Epidermal growth factor activates calcium channels by phospholipase A2/5-lipoxygenase-mediated leukotriene C4 production, Cell 69 (1992) 295-303.

[19] C.M. Peppiatt, A.M. Holmes, J.T. Seo, M.D. Bootman, T.J. Collins, F. McDonald, H.L. Roderick, Calmidazolium and arachidonate activate a calcium entry pathway that is distinct from store-operated calcium influx in HeLa cells, Biochem. J. 381 (2004) 929-939.

[20] O. Mignen, J.L. Thompson, T.J. Shuttleworth, $\mathrm{Ca}^{2+}$ selectivity and fatty acid specificity of the noncapacitative, arachidonate-regulated $\mathrm{Ca}^{2+}$ (ARC) channels, J. Biol. Chem. 278 (2003) 10174-10181.

[21] Z. Moneer, J.L. Dyer, C.W. Taylor, Nitric oxide co-ordinates the activities of the capacitative and non-capacitative $\mathrm{Ca}^{2+}$-entry pathways regulated by vasopressin, Biochem. J. 370 (2003) 439-448.

[22] D. Luo, L.M. Broad, G.S. Bird, J.W. Putney Jr., Mutual antagonism of calcium entry by capacitative and arachidonic acid-mediated calcium entry pathways, J. Biol. Chem. 276 (2001) 20186-20189.

[23] H. Ohvo, J.P. Slotte, Cyclodextrin-mediated removal of sterols from monolayers: effects of sterol structure and phospholipids on desorption rate, Biochemistry 35 (1996) 8018-8024.

[24] O. Mignen, T.J. Shuttleworth, Permeation of monovalent cations through the non-capacitative arachidonate-regulated $\mathrm{Ca}^{2+}$ channels in HEK293 cells. Comparison with endogenous store-operated channels, J. Biol. Chem. 276 (2001) 21365-21374.

[25] E.L. Watson, K.L. Jacobson, J.C. Singh, D.H. DiJulio, Arachidonic acid regulates two $\mathrm{Ca}^{2+}$ entry pathways via nitric oxide, Cell Signal. 16 (2004) $157-165$

[26] A. Gamberucci, R. Fulceri, A. Benedetti, Inhibition of store-dependent capacitative $\mathrm{Ca}^{2+}$ influx by unsaturated fatty acids, Cell Calcium 21 (1997) 375-385.

[27] S.R. Alonso-Torre, J. Garcia-Sancho, Arachidonic acid inhibits capacitative calcium entry in rat thymocytes and human neutrophils, Biochim. Biophys. Acta 1328 (1997) 207-213.

[28] O. Mignen, J.L. Thompson, T.J. Shuttleworth, Calcineurin directs the reciprocal regulation of calcium entry pathways in nonexcitable cells, J. Biol. Chem. 278 (2003) 40088-40096.

[29] T.P. Lockwich, X. Liu, B.B. Singh, J. Jadlowiec, S. Weiland, I.S. Ambudkar, Assembly of Trp1 in a signaling complex associated with caveolin-scaffolding lipid raft domains, J. Biol. Chem. 275 (2000) 11934-11942.

[30] I.S. Ambudkar, S.C. Brazer, X. Liu, T. Lockwich, B. Singh, Plasma membrane localization of TRPC channels: role of caveolar lipid rafts, Novartis Found. Symp. 258 (2004) 63-70 (discussion 70-74, 98-102, 263-266).

[31] I.S. Ambudkar, Cellular domains that contribute to $\mathrm{Ca}^{2+}$ entry events, Sci. STKE (2004) pe32.

[32] H. Li, L.M. Ayer, J. Lytton, J.P. Deans, Store-operated cation entry mediated by CD20 in membrane rafts, J. Biol. Chem. 278 (2003) 42427-42434.

[33] C. Kunzelmann-Marche, J.M. Freyssinet, M.C. Martinez, Loss of plasma membrane phospholipid asymmetry requires raft integrity. Role of transient receptor potential channels and ERK pathway, J. Biol. Chem. 277 (2002) 19876-19881.

[34] M.J. Aman, K.S. Ravichandran, A requirement for lipid rafts in B cell receptor induced $\mathrm{Ca}\left({ }^{2+}\right)$ flux, Curr. Biol. 10 (2000) 393-396. 